\title{
O ideal da consolação e a paixão pela morte
}

Paulo José Carvalho da Silva

A arte de consolar alguém que sofre tem uma longa história. Alguns pensadores tornaram-se uma referência fundamental no Ocidente e seus escritos exerceram importante influência, sobretudo na tradição da medicina da alma. É o caso de Sêneca, herdeiro inovador do estoicismo antigo, que escreveu a Consolação a Márcia (Ad Marciam de Consolatione) entre os anos 37 e 41, na Roma sob o governo de Calígula. Essa carta pública endereçada a uma nobre dama romana que perdera um filho é considerada a obra mais antiga conhecida e datada desse homem político e pensador, nascido em Córdova, no ano 4 a.C e morto no ano 65, e é, sem dúvida, um texto de grande interesse para a compreensão da antiga prática da consolação.

Palavras-chave: Consolação, estoicismo, medicina da alma, Sêneca 
A arte de consolar alguém que sofre tem uma longa história. Alguns pensadores tornaram-se uma referência fundamental no Ocidente e seus escritos exerceram importante influência, sobretudo na tradição da medicina da alma. É o caso de Sêneca, herdeiro inovador do estoicismo antigo, que escreveu a Consolação a Márcia (Ad Marciam de Consolatione) entre os anos 37 e 41, na Roma sob o governo de Calígula. Essa carta pública endereçada a uma nobre dama romana que perdera um filho é considerada a obra mais antiga conhecida e datada desse homem político e pensador, nascido em Córdova, no ano 4 a.C e morto no ano 65, e é, sem dúvida, um texto de grande interesse para a compreensão da antiga prática da consolação.

A pessoa consolada em questão, Márcia, era a filha de um senador, Cremutius Cordus que, uma dúzia de anos antes, havia visto seu livro sobre as guerras civis condenado e se suicidara. Márcia perdeu um de seus quatro filhos e três anos depois Sêneca escreveu para convencê-la de que não deveria prolongar o sofrimento desencadeado com a morte de seu filho. Hoje, talvez, chamássemos tal procedimento de aconselhamento psicológico ou terapia breve por meio do fortalecimento do Eu. Naquele tempo, o emprego do discurso, em um diálogo, a fim de ensinar a superação racional das paixões tristes e dores da alma se chamava consolação.

Vale lembrar que a história dessa prática não se restringe aos tempos dos imperadores romanos. McClure (1991) observa que a literatura dos séculos XIV e XV revitalizou a produção de manuais de consolação nos contextos retórico, filosófico, social e religioso, dando novo impulso ao antigo gênero e provocando uma redescoberta de autores como Sêneca em um momento decisivo para os fundamentos do pensamento moderno sobre o sofrimento humano.

A antiga consolação visava informar o público em geral, não apenas o seu destinatário declarado. Havia uma tensão entre o particular e o universal na elaboração do texto, no qual a experiência pessoal referida era erigida ao estatuto de exemplo e servia como modelo para a 


\section{$\begin{array}{lllllll}R & E & V & I & S & T & A\end{array}$ \\ LATIN O AMERICANA \\ DE PSICO PATO LOGIA \\ F U N D A M E N T A L \\ ano $X$, n. $1, \operatorname{mar} / 2007$}

aplicação de preceitos filosóficos e morais, genéricos, muitos deles consagrados pelo senso comum. O que não significava, por outro lado, desconsiderar aspectos biográficos particulares e a avaliação do modo e tempo oportunos para a consolação em cada caso.

Antes de Sêneca, Túlio Cícero (106-43 a.C.), outro moralista da Roma antiga, afirmava que um bom consolador deve comunicar a maneira de suportar os males referindo-se aos que o fizeram de maneira sábia. E o modo de fazer isso não pode ser genérico e imutável. Como nas defesas públicas, em que se adapta os argumentos às circunstâncias, à espécie de discussão e à pessoa, no ofício da consolação é necessário mensurar qual é o remédio mais adequado para cada um.

Cícero apresenta algumas orientações gerais a serem cuidadosamente administradas na consolação a fim de restaurar a soberania da razão. Conforme o terceiro livro das Tusculanae Disputationes, o primeiro remédio para o pesar é a compreensão de que o assunto em questão não é verdadeiramente um mal; o segundo é a exposição de que o caso particular está relacionado à condição humana e, em terceiro lugar, o entendimento de que é irracional e vão deixar-se tomar por uma paixão.

Ele, com efeito, retomou a oratória como um potente modo de agir sobre a alma e conferiu grande valor à arte de consolar. Foi sobretudo nessa tradição que a filosofia se firmou, mais do que nunca, como arte de viver ou cuidado de si, também cultivado por Sêneca, bem como outros pensadores antigos preocupados com a autodisciplina (Foucault, 1985).

Os escritos consolatórios podiam ter diferentes objetivos. A Consolação a minha mãe Helvia (Ad Helviam matrem de Consolatione), também de Sêneca, foi escrita no exílio, imposto pelo imperador Cláudio, sob a acusação de adultério, supostamente com sua sobrinha. Da Córsega, onde passaria dez anos, Sêneca consola sua mãe que, privada de sua presença, o supõe infeliz. Os argumentos consistem na afirmação de que o exílio não é motivo de sofrimento pois somos todos cidadãos do mundo. Sêneca constrói, nessa consolação, a imagem de sua família como sendo preocupada e amorosa e a imagem de si mesmo como um filósofo sereno. Mais do que isso, ao consolar a mãe, ele afirma-se superior ao triunfo dos seus inimigos.

Já na Consolação a Polibius (Ad Polybium de Consolatione), Sêneca consola o ministro de Cláudio que perdera um irmão mais novo e, ao mesmo tempo, suplica pela clemência do imperador e pede seu retorno a Roma. Em 49 d.C., Messalina, primeira esposa do imperador Cláudio e verdadeira responsável pelo exílio de Sêneca, foi condenada à morte. Algum tempo depois, Agripina, nova esposa do imperador, mandou chamar Sêneca para que este cuidasse da educação de seu filho, Nero. Em 54 d.C., quando Nero se tornou imperador, 
Sêneca passou a ser seu principal conselheiro. Em 62, porém, Sêneca deixou a vida pública e sofreu a perseguição do antigo aluno, que acabou por condená-lo ao suicídio.

Mesmo relacionadas a circunstâncias e motivos particulares, as idéias supostas consolatórias transmitiam alguns princípios universais, condizentes com a filosofia moral estóica. Como a doutrina estóica das paixões estabelece que as perturbações da alma têm origem em uma idéia falsa sobre um objeto ou acontecimento, a consolação também se daria com o processo de persuasão de que o sofrimento teria origem em uma idéia falsa. Sobretudo na intensidade da tristeza ou no seu prolongamento.

Sêneca também difundia esses lugares-comuns da doutrina estóica em outros gêneros de escritos, como as célebres Cartas a Lucílio. Escritas desde o verão de 62, esses documentos da correspondência com o amigo Lucílio também sintetizam os princípios da impassibilidade e da invulnerabilidade do sábio frente aos golpes da Fortuna, a necessidade de se libertar das paixões e, enfim, o elogio da razão que aproxima os homens do divino. Em particular, na Carta LXIII Não se deve chorar excessivamente a morte de um amigo, Sêneca volta a aplicar tais preceitos ao caso específico da dor da perda e insiste não apenas na superação da dor, mas em um certo decoro na sua experiência, como veremos exemplificado adiante.

Lucílio, na ocasião, chorava a morte do amigo Flaccus. Sêneca, então, inicia a carta afirmando que não gostaria que ele se afligisse mais do que o racional. Ele escreve que não ousaria pedir, porém, que ele não sofresse em absoluto, embora fosse melhor. Na continuação, o consolador afirma que haveria uma mistura de prazer e dor na lembrança dos amigos mortos e que o prolongamento do luto comportaria algo mais do que a simples prova de afeição. Além disso, tal prova seria inútil, posto que tardia, e pode indicar que o tal amigo fora negligenciado em vida, questionamento que Sêneca também dirigira a Márcia, anos antes.

A dor deve ser vencida pela vontade. Eis um ideal consagrado pela tradição popular e bastante coerente com o estoicismo. Aliás, há ecos dessa idéia tanto no senso comum como em teorias e práticas psicoterapêuticas da atualidade, sem que se explicite, de maneira precisa, as verdadeiras matrizes culturais.

Nas palavras de Sêneca (2002):

Sei que as observações que vou acrescentar são banais; todos as fazem, mas isto é motivo para que eu as omita? Se não conseguimos pôr um fim na dor pela vontade, o tempo se encarregará de fazê-lo. Mas é uma vergonha para o sábio curar a própria dor simplesmente porque está cansado de sofrer. Abandona a tua dor antes de seres abandonado por ela, suplico-te! (p.122) 


\section{$\begin{array}{lllllll}R & E & V & \text { I } & S & T & A\end{array}$ \\ LATINOAMERICAN A \\ DE PSICO PATO LOGIA \\ F U N D A M E N T A L \\ ano $X$, n. $1, \operatorname{mar} / 2007$}

Na realidade, esse ideal do sábio soberano à paixão, retomado ao longo da história do pensamento ocidental, já havia sido tratado por Cícero. E isso dentro de uma tentativa de defender a posição dos antigos estóicos, como Zenão (300 a.C.), face às doutrinas dos peripatéticos, dos epicuristas e de outras escolas de pensamento.

Nas Tusculanae Disputationes, Cícero afirma que o bem soberano é a virtude. Ele desenvolve essa idéia nas cinco partes do livro, nas quais defende que o sábio não teme a morte e a dor, ele resiste à tristeza e às paixões e a sabedoria é suficiente para assegurar a felicidade. Ele afirma que a dor pode não ser fácil de suportar, mas não haveria mal pior do que a ignomínia moral.

Todos esses temas são retomados por Sêneca e, em especial, a posição do sábio frente à dor. Não é que a dor seja irreal. O que não é natural, nem racional, é fixar-se na dor, o que também se lê na Consolação a Márcia, entre outros escritos. No De tranquilitate animae, que aborda o problema das atribulações da vida pública; ele desenvolve, por exemplo, a idéia segundo a qual a vida é uma escravidão e, portanto, é necessário acostumar-se a essa condição, reclamar o menos possível e aproveitar as oportunidades que ela oferece. Para superar os obstáculos e manter a alma imperturbável, ideal do sábio, é imprescindível viver conforme a razão. Trata-se do próprio objetivo da filosofia como cuidado de si. Ou melhor, como medicina da alma, o que se pode constatar na confissão atribuída a Serenus, com o qual se dá o diálogo:

Contudo o estado em que eu me surpreendo mais (por que não te confessar a verdade como a um médico?), é o de não estar completamente liberado dos meus temores e aversões passadas, sem todavia reincidir neles. Minha situação, por não ser a pior de todas, é extremamente lamentável e difícil: encontro-me entre a doença e a saúde. (Sêneca, 1962, p. 659, trad. nossa)

É justamente aos não completamente sadios (males sanos) que se endereçam as proposições de Sêneca. Aquele que se encontra nesse estado deve servir-se, conforme a vontade e o próprio passo, do remédio comum (publico remedio), notadamente, os meios segundo os quais se pode alcançar a tranqüilidade da alma, definida como o acordo dela consigo mesma, o prazer constante com os próprios bens, e, ao mesmo tempo, o estado intermediário entre a exaltação e o abatimento.

Como explica Voelke (1993), o dever da filosofia consiste em medicar a ignorância e o vício, considerados enfermidades. O objetivo é atingir a saúde da alma, caracterizada por uma disposição interna própria de uma alma virtuosa e sábia, que se posiciona em consentimento com a ordem universal, regrada pelo destino. Nesse sentido, a realização de tal filosofia, ou medicina da alma, exige uma espécie de disciplina do desejo, isto é, conformar os desejos à vontade da natureza universal, ao aceitar com alegria o curso dos eventos. Visto que a saúde 
a qual se visa é a do mundo, entendido como organismo que possui o homem como parte integrante de si, trata-se de harmonizar o desejo para colaborar com um projeto cósmico que ultrapassa e engloba o indivíduo. Conformando o desejo à ordem fixada pelo destino, supera-se a condição condenável de paixão, transmudando-a em vontade racional.

Para confortar aqueles que se sentem lesados pela morte de um próximo, Sêneca, no Consolação a Márcia, também enfatiza as mazelas e a fragilidade da vida. Assim, reitera a idéia de que a vida é um longo sofrimento, sendo a morte, portanto, um alívio. Lembra que os seres humanos não possuem verdadeiramente nada do que está à sua volta e que a vida é uma fuga incessante. Frisa o quanto o homem está sob o julgo da Fortuna. E, sobretudo, insiste na consciência inexorável da mortalidade. Ele chega mesmo a afirmar que o homem é um vaso que se quebra facilmente. Esse tema seria retomado no De brevitate vitae (4955), diálogo travado com seu futuro sogro, o nobre Paulinus, no qual Sêneca sustenta a tese de que a vida é caduca e o que mais importa é se dedicar a uma empresa intelectual que não depende da Fortuna e não recai no nada.

De modo particularizado, Sêneca lança a Márcia a interrogação que deveria fazê-la tomar o devido distanciamento racional de seus sofrimentos. Ele questiona em quê a morte de seu filho verdadeiramente a afeta. Ele o faz para examinar as supostas contradições em se lamentar por não haver gozado suficientemente da presença do ser amado ou do quanto ainda teria podido gozar se não o tivesse perdido. No fim demonstra, de modo generalizante, o quanto é raro que um grande bem seja também durável.

Um importante pressuposto da consolação estóica é que tudo o que nos inquieta é resultado de nossa escolha de nos apegarmos a uma idéia. Há também a oposição entre aquilo que depende de nós e aquilo que não depende. O que depende de nós é o presente, ocasião para a ação, a decisão e a liberdade. Na Carta I - O emprego do tempo, Sêneca (2002) escreve a Lucílio: “Tudo o que pertence ao passado é do âmbito da morte (...) Serás menos escravo do amanhã, se te tornares dono do presente” (p. 153).

Conforme Marco Aurélio (121-180), imperador e filósofo romano, continuador do estoicismo, o passado e o futuro não dependem de nosso poder: eles representam somente penas e prazeres imaginários. Não é uma recusa do pensamento do passado ou do futuro, mas, mais uma vez, das paixões desencadeadas por este pensamento, as vãs esperanças e a nostalgia (Hadot, 1995, p. 294).

A carta consolatória de Sêneca para Márcia termina com um elogio à morte que transcende o campo da filosofia, tangencia o poético (as referências ao poeta latino Virgilio, 70-19 a.C., intensificam-se) e flerta com o domínio do místico, como, por exemplo, na ratificação da teoria, endossada pelos estóicos, de que 


\section{$\begin{array}{lllllll}R & E & V & I & S & T & A\end{array}$ \\ LATIN O AMERICANA \\ DE PSICOPATO LOGIA \\ F U N D A M E N T A L \\ ano $X$, n. $1, \operatorname{mar} / 2007$}

cada indivíduo teria um destino previamente definido. Depreende-se que todos aqueles que choram a morte de um ente querido deveriam lembrar-se de que a vida é breve, de que somos apenas hóspedes de passagem e de que a morte é, na realidade, uma felicidade.

Sêneca se mostra consciente da possível inatingibilidade de tal postura perante a dor da perda. Ele até mesmo admite soar cruel, mas afirma que o sofrimento faz parte da condição humana, do mesmo modo que a experiência da beleza e do prazer. Além disso, a ética que ele busca difundir exige uma atenção a si mesmo, uma vigilância constante, e supõe uma renovação de si mesmo e, a cada instante, uma escolha de vida.

Justamente por pressupor a possibilidade da escolha racional, Sêneca anuncia, logo no início da carta, que inverterá o costume de se começar a consolação com os preceitos e finalizá-la com os exemplos, e relata dois casos opostos, notadamente, as experiências distintas de dor da perda, vividas, por volta de meio século antes, por Octavia e Lívia, respectivamente a irmã e a esposa do imperador Augusto (63 a.C.-14).

Octavia perdeu seu filho Marcelo, jovem vivaz e virtuoso, bem cotado para a sucessão ao trono de seu tio. Durante o resto de sua vida, Octavia chorou e gemeu, jamais aceitou uma palavra de conforto, nunca procurou por algum tipo de distração, absorvida por um pensamento que a tomava por completo. Ela permaneceu toda a sua vida no mesmo estado do dia do funeral de seu filho. Não lhe faltava energia, mas ela recusava qualquer alegria, temendo dobrar sua miséria ao perder a felicidade que ela encontrava em suas lágrimas. Entretanto, ela não quis guardar nenhuma imagem de seu filho querido. Octavia detestava todas as outras mães, em especial, Lívia, cujo filho poderia herdar a felicidade que ela esperava ser de Marcelo. Tendo gosto apenas pela obscuridade e pela solidão, recusava mesmo a companhia de seu irmão e, mais, rejeitava todas as homenagens prestadas à memória de seu filho. Subtraiu-se às cerimônias oficiais e ao convívio social. Em família, junto aos filhos e netos, guardou perpetuamente as vestimentas de luto, para grande humilhação dos mesmos que presenciavam sua insistência em portar-se como se estivesse só no mundo.

Ao ler a história de Octavia é impossível não lembrar da noção freudiana de luto patológico e de melancolia, cunhada tantos séculos depois, em 1917, cujo quadro sintomático corresponde a um estado de ânimo profundamente doloroso, cessação do interesse pelo mundo exterior, perda da capacidade de amar, inibição e diminuição do amor próprio.

Já o caso de Lívia lembra o processo de luto suposto normal. Ela perdeu seu filho Drusus, grande príncipe, durante uma campanha na Germânia, para imensa desolação não apenas de sua família, mas de muitos cidadãos romanos e mesmo das províncias, que prestigiaram seu cortejo fúnebre em direção a Roma. 
Lívia não pôde presenciar os últimos momentos de seu filho, mas acompanhou seus restos mortais no longo percurso pela Itália, por onde as homenagens inflamadas renovavam o sentimento da perda e reavivavam sua dor. Entretanto, assim que ela pôde depositar os restos de Drusus na tumba, ela igualmente sepultou seu filho e seu sofrimento. Segundo Sêneca, ela não se afligia além do que se espera de uma mulher que goza da alegria de ter seu marido, o imperador, e um outro filho ainda vivos. Entretanto, ela jamais deixou de pronunciar o nome de seu filho, de contemplar constantemente imagens dele, em âmbito particular ou público, de comprazer-se em falar sobre ele ou ouvir falarem dele. Enfim, Lívia experimentou um luto finito, pôde elaborar a perda e viveu com a memória de seu filho.

Após expor esses dois exemplos de modelos distintos de sofrimento, Sêneca convoca Márcia a refletir sobre as vantagens de se evitar um estado d’alma no qual se cultiva uma disposição em que se mostra tão lasso de viver quanto incapaz de morrer e adotar uma outra disposição conforme a qual não se aumenta voluntariamente seu próprio mal ao se deixar consumir pelo pesar, nem gozar do martírio.

A partir do texto de Sêneca, pode-se pensar que o luto prolongado seria uma recusa da continuidade e do fim. Isto é, uma disposição anímica que parece ou prefere ignorar tanto a dor inevitável da vida quanto a consciência de que ela é finita. Efeito de uma certa paixão pela idéia da morte?

Fala-se também em paixão pela morte, o que é diferente da escolha pelo fim da vida. Sêneca viria a escrever a Lucílio, na Carta XXIV - o medo do futuro - a morte, que a moral estóica manda evitar amar demais a vida ou detestá-la. Mesmo admitindo que o suicídio é uma saída honrada quando não se pode mais viver como homem livre, Sêneca (2002) condena a paixão pela morte:

Sim, meu caro Lucílio, há paixão pela morte como por outros objetos; tal paixão provoca em nossa alma um desejo insensato, que geralmente tem por vítima homens generosos e dotados de grande força de caráter, bem como homens covardes e frouxos: uns desprezam a vida, outros se sentem oprimidos por ela. Alguns se cansam de ver e de fazer sempre a mesma coisa: eles não detestam a vida, estão desgostosos dela. (...) Para muitos, a vida não é dolorosa, porém inútil. (p. 100)

Gostaria de finalizar com um questionamento que é ao mesmo tempo um convite à leitura do Consolação a Márcia. A psicanálise nos libertou de um ideal de consolação e subverteu qualquer expectativa de uma superação racional da dor, propondo, no lugar, um dispositivo para a elaboração psíquica da mesma. Entretanto, a tradição da medicina da alma continua a nos inspirar a reformulação de antigas questões ainda muito pertinentes: seria a paixão pela morte mais uma 
L'art de consoler quelqu'un qui souffre possède une longue histoire. Certains penseurs représentent une référence fondamentale en Occident et leurs oeuvres ont exercé une influence importante, surtout dans la tradition de la médecine de l'âme. C'est le cas de Sénèque, héritier innovateur de l'ancien stoïcisme, auteur de Consolation à Marcia (Ad Marciam de Consolatione) entre 37 e 41, à Rome, sous le règne de Caligula. Cette lettre publique qui s'adresse à une dame de la noblesse romaine qui avait perdu un enfant est considérée l'oeuvre la plus ancienne connue et datée de ce philosophe et homme politique né à Cordoue, en 4. av. J.-C. et mort en 65. Il s'agit sans doute d'un texte de grand intérêt pour comprendre l'ancienne pratique de la consolation.

Mots clés: Consolation, stoïcisme, médecine de l’âme, Sénèque

The art of consoling those who are suffering has a long history. Some thinkers eventually became basic references in this respect in the West, and their writings exercised major influence, especially in the tradition of the medicine of the soul. One such writer was Seneca, an innovative heir of early stoicism, who wrote Consolation to Márcia (Ad Marciam de Consolatione) between the years 37 and 41 A.D., in Rome, which was then under the rule of Caligula. This public letter addressed to a Roman noblewoman who had lost a son is considered the oldest known and dated work of this great politician and thinker. He was born in Cordoba in the year 4 B.C. and died in 65. This famous letter is a text of major interest to those who wish to understand the ancient practice of consolation.

Key words: Consolation, stoicism, medicine of the soul, Seneca 